\title{
Spectrofluorimetric Determination of Oxamniquine in Dosage Forms and Spiked Human Plasma through Derivatization with 1-dimethylaminonaphthalene-5-sulphonyl chloride
}

\author{
N. El-Enany $•$ F. Belal $•$ M. Rizk
}

Received: 5 September 2007 / Accepted: 16 October 2007 /Published online: 5 December 2007

(C) Springer Science + Business Media, LLC 2007

\begin{abstract}
A sensitive, simple and selective spectrofluorimetric method was developed for the determination of oxamniquine (OXM) in pharmaceutical formulations and biological fluids. The method is based on the reaction between the drug and 1-dimethylaminonaphthalene-5sulphonyl chloride (dansyl chloride) in presence of $0.5 \mathrm{M}$ sodium carbonate $(\mathrm{pH} 10)$ to yield a highly fluorescent derivative that is measured at $445 \mathrm{~nm}$ after excitation at $335 \mathrm{~nm}$. The different experimental parameters affecting the development and stability of the reaction product were carefully studied and optimized. The fluorescence concentration plot was rectilinear over the range of $0.02-0.2 \mu \mathrm{g} \mathrm{ml}^{-1}$ with a lower detection limit (LOD) of $0.007 \mu \mathrm{g} \mathrm{ml}^{-1}$ and limit of quantitation (LOQ) of $0.02 \mu \mathrm{g} \mathrm{ml} \mathrm{m}^{-1}$. The proposed method was successfully applied to the analysis of commercial capsules. The results obtained were in good agreement with those obtained using the official spectrophotometric method. Furthermore, the method was applied for the determination of oxamniquine in spiked human plasma, the mean \% recovery $(n=4)$ is $97.77 \pm 1.19$. A proposal of the reaction pathway was presented.
\end{abstract}

N. El-Enany $(\bowtie) \cdot$ F. Belal

Department of Analytical Chemistry, Faculty of Pharmacy,

University of Mansoura,

35516 Mansoura, Egypt

e-mail: nelenany1@yahoo.com

M. Rizk

Department of Analytical Chemistry, Faculty of Pharmacy, University of Helwan,

Cairo, Egypt
Keywords Oxamniquine - 1-dimethylaminonaphalene5-sulphonyl chloride · Dosage forms · Spiked human plasma

\section{Introduction}

Oxamniquine (OXM), 1,2,3,4-tetrahydro-2[(isopropylamino methyl]-7-nitro-6-quyinoline methanol is an antischistosomal agent that is indicated for the treatment of schistosoma mansoni (intestinal schistosomiasis) infection (Fig. 1). It has been shown to inhibit DNA, RNA and protein synthesis in schistosomes. The oral bioavailability of oxamniquine is good and effective plasma levels are achieved in $1-1.5 \mathrm{~h} \mathrm{[1]}$.

Oxamniquine is the subject of a monograph in the USP (XXIII) [2] whereby a spectrophotometric method is recommended for its determination, whether in its pure form or in capsules. Several methods have been published for the determination of OXM, either per se or in pharmaceutical preparations and biological fluids. These methods include: spectrophotometry [3-5], non-aqueous titration [6], gas chromatography [7], HPLC [8-13], capillary electrophoresis [11], polarography [14], flow injection analysis [15], cyclic voltammetry [16] and fluorimetry [17].

All these methods are either insufficiently sensitive or tedious and require highly sophisticated and dedicated instrumentation [8-13]. This led us to study the reaction of oxamniquine with dansyl chloride to develop simple and sensitive spectrofluorimetric method for its determination in pharmaceutical preparations and biological fluids. Dansyl chloride is a useful derivatizing agent for primary amines, secondary amines, imidazoles and phenols, etc.. Several pharmaceutical compounds have been determined through this approach [18-24]. 
<smiles>CCCNCC1CCc2cc(C=O)c([N+](=O)[O-])cc2N1</smiles>

Fig. 1 Structural formula of oxamniquine

The reported spectrofluorimetric method for oxamniquine [17] is tedious and time consuming. It involves the use of 2-cyanoacetamide, a hazard reagent.

\section{Experimental}

\section{Apparatus}

The spectrofluorimetric measurements were recorded using ARF-1501 Shimadzu Spectrofluorometer, equipped with Xenon arc lamp.

\section{Materials and reagents}

All reagents and solvents were of analytical reagent grade

- Oxamniquine pure sample was kindly provided by Pfizer (Sandwich, UK).

- Capsules containing $250 \mathrm{mg}$ of Oxamniquine each (Vansil capsules) were obtained from commercial sources in the local market.

- 1-Dimethyl aminonaphthalene-5-sulphonyl chloride (dansyl chloride), purchased from Sigma (St. Louis, USA). A stock solution containing $0.1 \%$ of dansyl chloride was freshly prepared in acetone and was further diluted with the same solvent to obtain $0.001 \%$ solution.

- Sodium carbonate (BDH, UK) 0.5 M aqueous solution (pH 10).

- Sodium hydroxide (BDH, UK) $1 \mathrm{M}$ aqueous solution.

- Isobutylmethyl ketone (IBMK) (Merck, Darmstadt, Germany).

- Plasma was kindly provided by Mansoura University Hospital, and kept frozen until assay after gentle thawing.

- Methanol and diethyl ether (Merck, Darmstadt, Germany).

Standard solutions

A stock solution was prepared by dissolving $20.0 \mathrm{mg}$ of OXM in $20 \mathrm{ml}$ of acetone and $80 \mathrm{ml}$ of $0.5 \mathrm{M}$ sodium carbonate solution. This solution was further diluted with the same solvent mixture as appropriate. The standard solutions were stable for seven days when kept in the refrigerator.

General procedure

Aliquots of OXM standard solution were transferred into a series of $10 \mathrm{ml}$ volumetric flasks. $0.7 \pm 0.1 \mathrm{ml}$ of $0.001 \%$ of dansyl chloride reagent was added, followed by $0.4 \mathrm{ml}$ of acetone and mixed well. The reaction mixture was left for $30 \mathrm{~min}$, and then completed to the mark with IBMK. the reaction mixture was allowed to stand for $10 \mathrm{~min}$. The fluorescence intensity of the reaction product was measured at $445 \mathrm{~nm}$ after excitation at $335 \mathrm{~nm}$. Blank experiment was carried out simultaneously. The corrected fluorescence intensity was plotted vs the final drug concentration $\left(\mu \mathrm{g} \mathrm{ml} \mathrm{ml}^{-1}\right.$ ) to get the calibration graph. Alternatively, the corresponding regression equation was derived.

\section{Applications}

\section{Procedure for commercial capsules}

The content of ten capsules were emptied, and mixed well. A weighed quantity of the powder equivalent to $5.0 \mathrm{mg}$ OXM was transferred into a small conical flask, and extracted with $2 \times 10 \mathrm{ml}$ of methanol. The extract was filtered into $25 \mathrm{ml}$ volumetric flask. The conical flask was washed with several milliliters of methanol. The washing was passed into the same volumetric flask, and the combined extract was evaporated to dryness on a boiling water bath. The residue was dissolved and diluted to volume with a mixture of $5 \mathrm{ml}$ of acetone and $20 \mathrm{ml}$ of $0.5 \mathrm{M}$ of sodium carbonate solution. Aliquots covering the working concentration range (cited in Table 1) was

Table 1 Performance data of the proposed method

\begin{tabular}{ll}
\hline Parameter & Proposed method \\
\hline Concentration range $\left(\mu \mathrm{g} \mathrm{ml}^{-1}\right)$ & $0.02-0.2$ \\
Minimum detection limit, LOD $\left(\mu \mathrm{g} \mathrm{ml}^{-1}\right)$ & 0.007 \\
Limit of Quantification, LOQ $\left(\mu \mathrm{g} \mathrm{m}^{-1}\right)$ & 0.02 \\
Correlation coefficient $(\mathrm{r})$ & 0.9999 \\
Slope & $3,473.114$ \\
Intercept & 0.574 \\
$S_{y / x}$ & 1.273 \\
$S_{a}$ & 7.733 \\
$S_{b}$ & 8.965 \\
$\%$ Error & 0.28
\end{tabular}

$S_{y / x}=$ standard deviation of the residuals

$S_{a}=$ standard deviation of the intercept of regression line

$S_{b}=$ standard deviation of the slope of regression line

$\%$ Error $=\mathrm{RSD} \% / \sqrt{ } \mathrm{n}$ 
transferred into $10 \mathrm{ml}$ volumetric flasks. The "General procedure" was then applied. The nominal content of the capsules was determined either from the calibration curve or using the corresponding regression equation.

\section{Procedure for spiked human plasma}

A stock solution containing $20 \mu \mathrm{g} \mathrm{ml} \mathrm{m}^{-1}$ of OXM was prepared. Control samples of plasma was spiked with different quantities of OXM to give a final drug concentration cited in Table 5 . One molar $\mathrm{NaOH}(0.8 \mathrm{ml})$ was added to $1.0 \mathrm{ml}$ of the spiked plasma and shaken genteelly. The solution was vortexed with $3 \times 5 \mathrm{ml}$ of diethylether for $2 \mathrm{~min}$, then centrifuged at $2,500 \mathrm{rpm}$ for $5 \mathrm{~min}$. The resulting supernatant was evaporated to dryness under nitrogen at ambient temperature. The residue was dissolved and diluted to volume with a mixture of $5 \mathrm{ml}$ of acetone and $20 \mathrm{ml}$ of $0.5 \mathrm{M}$ of sodium carbonate solution. Aliquots covering the working concentration range was transferred into $10 \mathrm{ml}$ volumetric flasks. The recommended procedures were then applied. The nominal content of the drug was determined using the corresponding regression equation.

\section{Results and discussion}

Dansyl chloride was first introduced for the determination of some primary, secondary amines, imidazoles and phenols [18-20].

In recent reports. DNS was further used as a fluorogenic reagent for the determination of some pharmaceutical compounds [21-24].

In the present study, OXM was found to react with Dansyl chloride at $\mathrm{pH} 10.0$ forming a highly yellow fluorescent derivative with $\lambda$ maximum emission at $445 \mathrm{~nm}$ after excitation at $335 \mathrm{~nm}$ (Fig. 2).

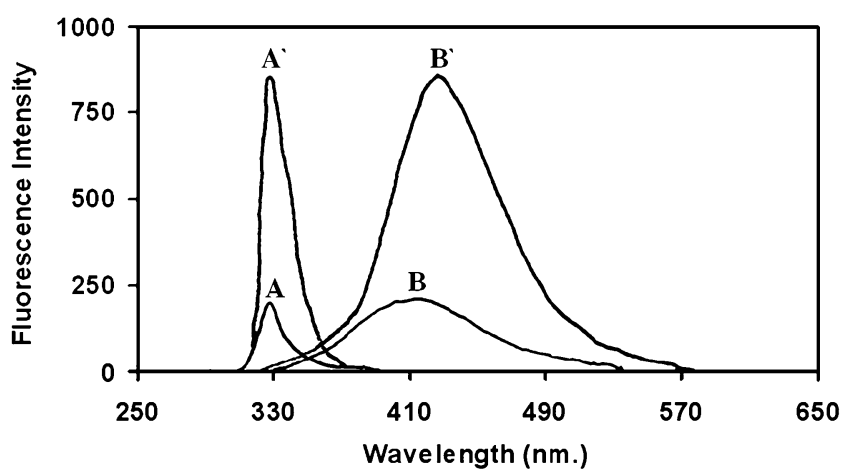

Fig. 2 Fluorescence spectra of $A$ and $B$ excitation and emission spectra of blank. Fluorescence spectra of $A^{\prime}$ and $B^{\prime}$ excitation and emission spectra of oxamniquine $\left(0.2 \mu \mathrm{g} \mathrm{ml}^{-1}\right)$ with dansyl chloride at $\mathrm{pH} 10.0$
Optimization of experimental parameters

The spectrofluorimetric properties of the colored product as well as the different experimental parameters affecting the development of the reaction product and its stability were carefully studied and optimized. Such factors were changed individually while the others were kept constant. The factors include $\mathrm{pH}$, concentration of the reagent, type of buffer, temperature, reaction time and dilution time.

\section{Effect of $p H$}

The influence of $\mathrm{pH}$ on the fluorescence intensity of the reaction product was studied. Maximum fluorescence intensity was obtained upon using mixture of acetone and $0.5 \mathrm{M}$ sodium carbonate solution. The $\mathrm{pH}$ of the reaction mixture was found to be 10.0. $\mathrm{pH} 10$ was found to be the optimum $\mathrm{pH}$ for dansylation because labeling of most amino acids, amines, imidazoles and phenols has been found to be optimal at $\mathrm{pH}$ 9.5-10.5 [25]. The rate of dansylation process was found to increase with increasing the $\mathrm{pH}$ value this is due to an increase in the rate of hydrolysis of dansyl chloride into dansyl hydroxide [25]. The latter shows strong fluorescence and hence interferes seriously in the determination. However, under the proposed chosen conditions and wavelengths used, there was no interference arising from any dansyl hydroxide formed, as indicated by the low fluorescence intensity of the reagent.

\section{Effect of concentration of dansyl chloride}

The influence of the concentration of dansyl chloride was studied using different volumes of $0.001 \%$ of the reagent solution. It was found that, the reaction of dansyl chloride with OXM started upon using $0.1 \mathrm{ml}$ of the reagent in the presence of sodium carbonate $(\mathrm{pH}$ 10.0). Increasing the volume of the reagent, produces a proportional increase in the fluorescence intensity of the reaction product up to $0.6 \mathrm{ml}$ and remains constant up to $0.8 \mathrm{ml}$. Therefore, $0.7 \pm$ $0.1 \mathrm{ml}$ of $0.001 \%$ of dansyl chloride solution was chosen as the optimal volume of the reagent (Fig. 3).

\section{Effect of temperature}

Increasing the reaction temperature higher than the room temperature would result in a subsequent decrease in the fluorescence intensity of the reaction product.

\section{Effect of reaction time}

Different time intervals were tested to ascertain the time after which the solution attains its highest fluorescence intensity. It was found that after $30 \mathrm{~min}$, the reaction 


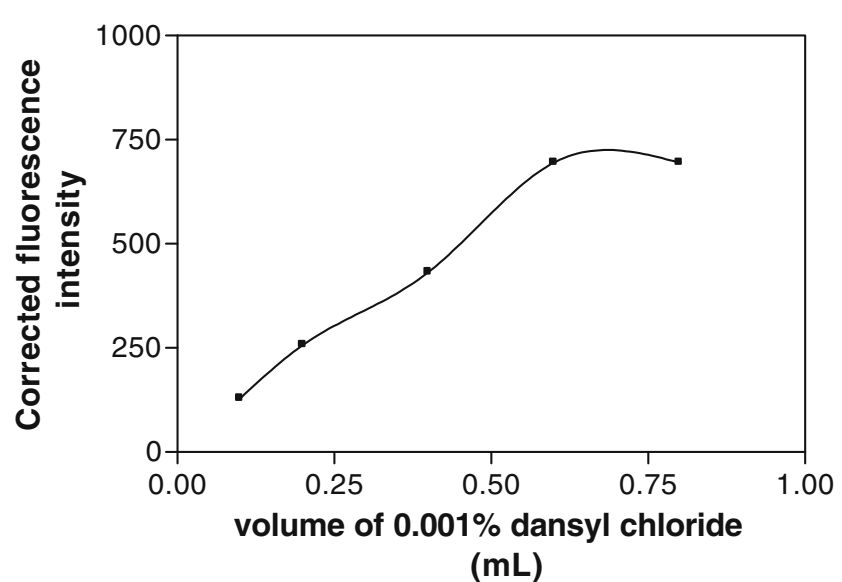

Fig. 3 Effect of volume of dansyl chloride $(0.001 \%)$ on the fluorescence intensity of the reaction product of oxamniquine $\left(0.2 \mu \mathrm{g} \mathrm{m}^{-1}\right)$ at $\mathrm{pH} 10.0$

product reaches the highest fluorescence intensity (Fig. 4) and remains stable at room temperature for $20 \mathrm{~min}$.

\section{Effect of diluting solvent}

Different solvents were tried to dilute the reaction mixture through out the study. It was observed that isobutyl methyl ketone gave the highest fluorescence intensity. Dilution with $0.5 \mathrm{M}$ sodium carbonate solution, water, acetonewater produced almost very week fluorescence and did not reduce the blank fluorescence intensity. While upon using isobutyl methyl ketone, the fluorescence intensity attained its highest value, this was attributed to the low fluorescence value of the reagent.

\section{Effect of dilution time}

Dilution times were tested to ascertain the time after which the solution attains its highest fluorescence. It was found

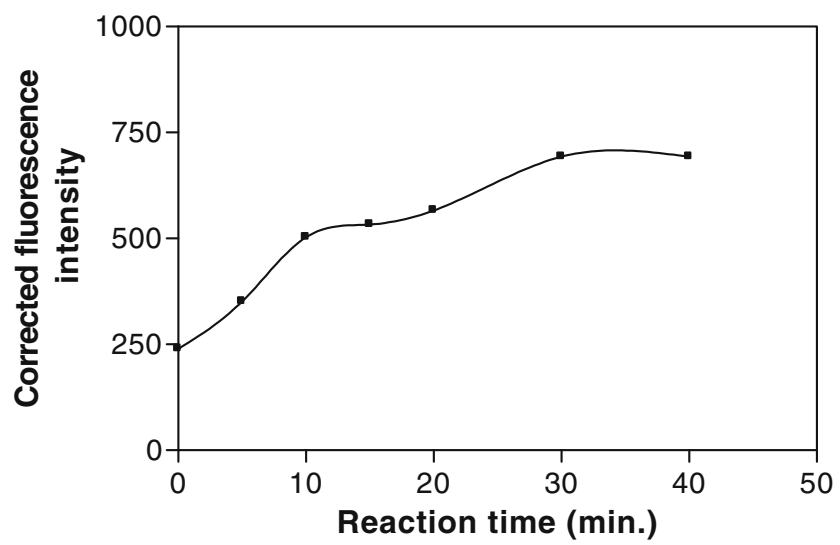

Fig. 4 Effect of reaction time of on the fluorescence intensity of the reaction product of oxamniquine $\left(0.2 \mu \mathrm{g} \mathrm{ml}^{-1}\right)$ with dansyl chloride that dilution with IBMK after $10 \mathrm{~min}$, the reaction product reaches its highest fluorescence intensity (Fig. 5).

Analytical performance

Validation of the proposed methods The validity of the method was tested regarding; linearity, specificity, accuracy, repeatability and precision according to ICH Q2B recommendations [26].

\section{Linearity}

By using the above procedure, linear regression equation was obtained. The regression plots showed that there was a linear dependence of the fluorescence intensity on the concentration of the drug over the ranges cited in Table 1. Linear regression analysis of the data gave the following equation:

$F=0.574+3,473.114 C \quad(r=0.9999)$

where $F$ is the fluorescence intensity, $C$ is the concentration of the drug in $\mu \mathrm{g} \mathrm{ml}^{-1}$ and $r$ is the correlation coefficient.

The limit of quantification (LOQ) was determined by establishing the lowest concentration that can be measured according to ICH Q2B [26]. The results are shown in Table 1. The limits of detection (LOD) were determined by establishing the minimum level at which the analyte can be reliably detected, and the results are also abridged in Table 1.

LOQ and LOD were calculated according to the following equation [26]:

$\mathrm{LOQ}=10 \sigma / S$

$\mathrm{LOD}=3.3 \sigma / S$

Where $\sigma$ : is the standard deviation of the intercept of regression line. $S$ : is the slope of the calibration curve.

The proposed methods were evaluated for the accuracy as percent relative error $(\% \mathrm{Er})$ and the precision as percent relative standard deviation (\% RSD) (Tables 1 and 2).

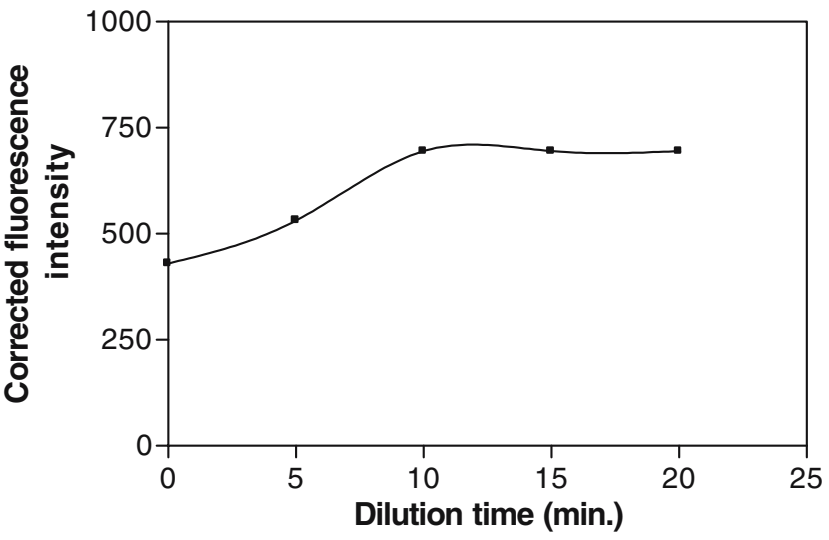

Fig. 5 Effect of dilution time on the fluorescence intensity of the reaction product of oxamniquine $\left(0.2 \mu \mathrm{g} \mathrm{ml}^{-1}\right)$ with dansyl chloride 
Table 2 Application of the proposed and official methods to the determination of Oxamniquine in pure form

\begin{tabular}{lcc}
\hline Parameters & $\begin{array}{l}\text { Spectrofluorimetric } \\
\text { method }\end{array}$ & $\begin{array}{l}\text { Official method } \\
{[2]}\end{array}$ \\
\hline No. of experiments & 6 & 3 \\
Mean found (\%) & 100.13 & 100.09 \\
$\quad \pm$ SD & 0.68 & 0.87 \\
$\%$ RSD & 0.68 & 0.87 \\
Variance & 0.462 & 0.76 \\
Student's $t$ value & $0.081(2.31)$ & \\
Variance ratio $F$ test & $1.65(5.41)$ & \\
\hline
\end{tabular}

Figures between parentheses are the tabulated $t$ and $F$ values respectively, at $p=0.05$ [27]

\section{Accuracy}

To test the validity of the proposed method it was applied to the determination of authentic sample of OXM over the working concentration range. The results obtained were in good agreement with those obtained using official method. Using Student's $t$ test and variance ratio $F$ test, [27] revealed no significant difference between the performance of the two methods regarding the accuracy and precision, respectively (Table 2 ).

The validity of the methods was proved by statistical evaluation of the regression lines, using the standard deviation of the residuals $\left(S_{y / x}\right)$, the standard deviation of the intercept $\left(S_{a}\right)$ and standard deviation of the slope $\left(S_{b}\right)$. The results are abridged in Table 1. The small values of the figures point out to the low scattering of the points around the calibration line and high precision.

Table 3 Validation of the proposed method for the determination of oxamniquine in pure form

\begin{tabular}{lrr}
\hline $\begin{array}{l}\text { Sample } \\
\text { concentration }\end{array}$ & $\begin{array}{l}\text { \% Recovery } \\
\text { (repeatability) }\end{array}$ & $\begin{array}{l}\text { \% Recovery intermediate } \\
\text { precision }\end{array}$ \\
\hline $0.08 \mu \mathrm{g} \mathrm{ml}^{-1}$ & 99.64 & 101.08 \\
& 100.72 & 99.28 \\
$X^{\prime}$ & 101.44 & 100.89 \\
$\pm \mathrm{SD}$ & 100.60 & 100.42 \\
$\% \mathrm{RSD}$ & 0.91 & 0.99 \\
$\%$ Error & 0.91 & 0.99 \\
$0.2 \mu \mathrm{g} \mathrm{ml}{ }^{-1}$ & 0.53 & 0.57 \\
& 99.74 & 101.05 \\
$X^{\prime}$ & 100.44 & 100.53 \\
$\pm \mathrm{SD}$ & 101.29 & 98.95 \\
$\% \mathrm{RSD}$ & 100.49 & 100.18 \\
$\%$ Error & 0.78 & 1.09 \\
\hline
\end{tabular}

Table 4 Application of the proposed methods to the determination of oxamniquine in capsules

\begin{tabular}{|c|c|c|}
\hline \multirow[t]{2}{*}{ Preparations } & \multicolumn{2}{|l|}{$\%$ Recovery } \\
\hline & Proposed method & Official method [2] \\
\hline $\begin{array}{c}\text { Vansil capsules (250 mg } \\
\text { oxamniquine/capsule) }\end{array}$ & $\begin{array}{r}98.25 \\
101.00 \\
99.38 \\
99.80 \\
99.30\end{array}$ & \\
\hline $\begin{array}{l}\text { Mean found }(\%) \pm \mathrm{SD} \\
t \text { value } \\
F \text { value }\end{array}$ & $\begin{array}{l}99.55 \pm 0.99 \\
1.67 \\
1.66\end{array}$ & $100.56 \pm 0.77$ \\
\hline
\end{tabular}

The tabulated values of $t$ and $F$ are (2.37) and (6.59) respectively, at $p=0.05$ [27]

\section{Precision}

\section{a. Repeatability}

The repeatability was performed by applying the proposed methods for the determination of two concentrations of OXM in pure form on three successive times, and the results are listed in Table 3.

b. Intermediate precision

It was performed through repeated analysis of OXM in pure form, using the concentrations showed in Table 3 for a period of three successive days. The results are summarized in Table 3.

\section{Robustness of the method}

The robustness of the method adopted is demonstrated by the constancy of the fluorescence intensity with the deliberated

Table 5 Application of the proposed methods to the determination of oxamniquine in spiked human plasma

\begin{tabular}{llll}
\hline Sample & $\begin{array}{l}\text { Amount added } \\
\left(\mu \mathrm{g} \mathrm{ml}^{-1}\right)\end{array}$ & $\begin{array}{l}\text { Amount found } \\
\left(\mu \mathrm{g} \mathrm{ml}^{-1}\right)\end{array}$ & \% Recovery \\
\hline 1-a-Plasma (inter- & 0.02 & 0.01957 & 97.85 \\
day precision) & 0.04 & 0.03856 & 96.40 \\
& 0.10 & 0.09754 & 97.54 \\
& 0.20 & 0.19856 & 99.28 \\
Mean & & & 97.77 \\
\pm SD & & & 1.19 \\
1-b-Plasma (inter- & 0.20 & 0.1914 & 95.70 \\
day precision) & 0.20 & 0.1969 & 98.45 \\
& 0.20 & 0.1948 & 97.40 \\
& 0.20 & 0.1955 & 97.75 \\
& 0.20 & 0.1979 & 98.95 \\
Mean & 0.20 & 0.1945 & 97.25 \\
\pm SD & & & 97.58 \\
\hline
\end{tabular}

Each result is the average of three separate determinations 

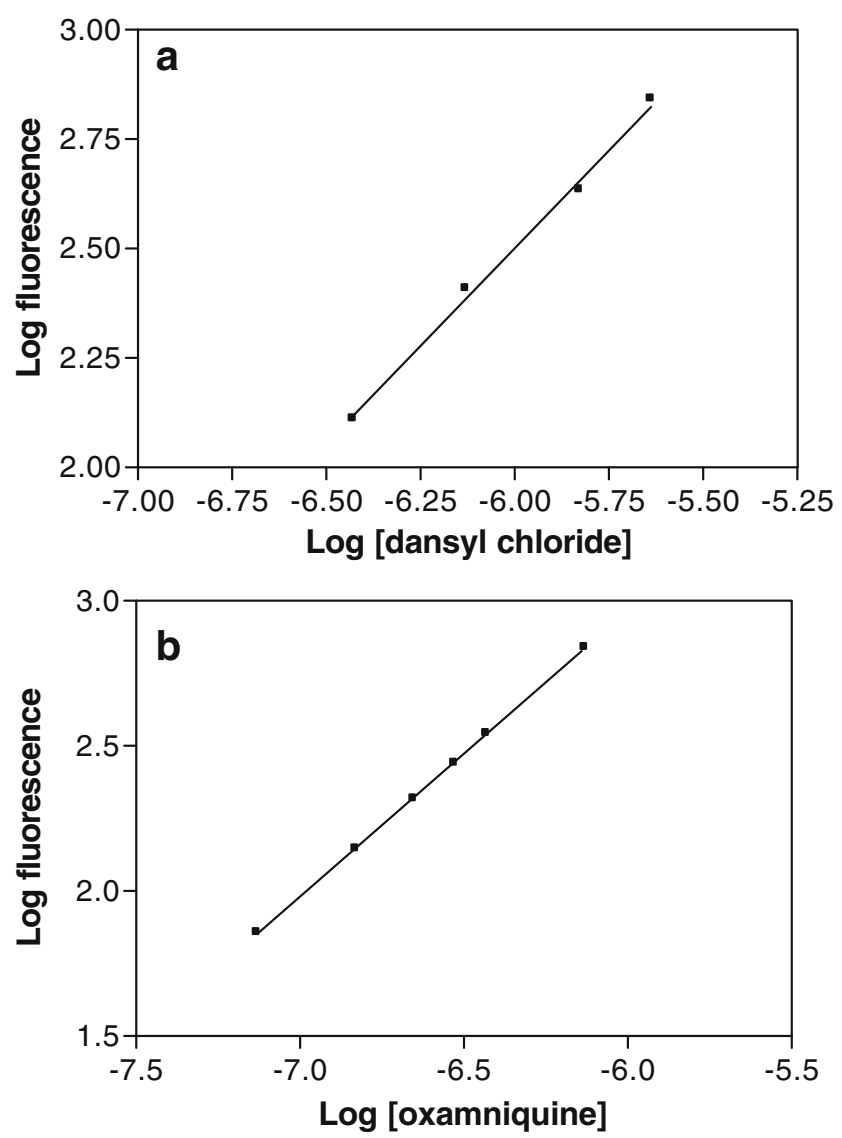

Fig. 6 Limiting logarithmic plots for the molar ratio. a Log F vs. Log [dansyl chloride]. b Log F vs. log [oxamniquine]

minor changes in the experimental parameters such as change in the volume of dansyl chloride $(0.001 \%), 0.7 \pm$ $0.1 \mathrm{ml}$, the change in reaction time $35 \pm 5 \mathrm{~min}$ and the change in dilution time $15 \pm 5 \mathrm{~min}$. These minor changes that may take place during the experimental operation didn't affect the fluorescence intensity of the reaction product.

\section{Pharmaceutical applications}

The proposed methods were then applied to the determination of OXM in its capsules. The methods were tested for linearity, specificity, accuracy, repeatability and precision according to $\mathrm{ICH}$ Q2B recommendations.

\section{Specificity}

The specificity of the method was investigated by observing any interference encountered from the common capsule excepients, such as talc, lactose, starch, avisil, gelatine, and magnesium stearate. These excepients did not interfere with the proposed method.

\section{Accuracy}

The results of the proposed methods were statistically compared with those obtained using the official method [2]. Statistical analysis [27] of the results, using Student's $t$ test and variance ratio $F$ test revealed no significant difference between the performance of the proposed and reference methods regarding the accuracy and precision, respectively (Table 4).

\section{Analysis of biological fluid}

The high sensitivity of the proposed method allowed the determination of OXM in spiked human plasma. Oxamniquine is readily absorbed following oral ingestion, and a peak concentration in plasma occurs within about $3 \mathrm{~h}$. The presence of food significantly delays absorption and limits the concentration achieved in plasma during the first several hours after administration. Urinary excretion is the major route of elimination in man [28]. Oxamniquine is given orally in a dose of $250 \mathrm{mg}$ three times daily; this leads to a final blood level concentration of about $5 \mu \mathrm{g} \mathrm{ml}^{-1}$ i.e. higher than the upper limit of the working concentration range of the proposed method. The high sensitivity of the proposed method allowed the determination of OXM in spiked human plasma. The results are shown in Table 5.

The extraction procedure described by Woolhouse and Wood [7] was adopted here. The results are satisfactorily accurate and precise.
Scheme 1 Proposed reaction pathway between dansyl chloride and oxamniquine<smiles>[R]N[PH2+]CCCCCCc1cccc2c(S(=O)(=O)N([R])[R])cccc12</smiles> 
Precision The within-day precision was evaluated through replicate analysis of Plasma samples spiked with different concentrations of the drug. The percentage recoveries based on the average of four separate determinations were $97.77 \pm 1.19$, thus indicating the high precision of the method (Table 5).

The inter-day precision was also evaluated through replicate analysis of plasma samples spiked with $0.2 \mu \mathrm{g} \mathrm{ml}^{-1}$ of drug on four successive days. The percentage recoveries based on the average of four separate determinations were $97.58 \pm 1.13$. The results are shown in Table 5.

\section{Mechanism of the reaction}

The stoichiometry of the reaction was studied adopting the limiting logarithmic method [29]. The fluorescence intensity of the reaction product was alternatively measured in the presence of excess of either dansyl chloride or OXM. A plot of $\log$ fluorescence versus log [dansyl chloride] and $\log$ [OXM] gave straight lines, the values of the slopes are 0.901 and 0.984 respectively (Fig. 6). Hence, it is concluded that, the molar reactivity of the reaction is $0.901 / 0.984$, i.e. the reaction proceeds in the ratio of $1: 1$. Based on the observed molar reactivity of the reaction, and depending on the presence of secondary amino group and by analogy to similar reports dealing with the reaction of dansyl chloride with compounds containing secondary amino group, the reaction pathway proposed in Scheme 1 is presented.

\section{Conclusion}

The proposed method has the advantage of being simple, sensitive and suitable for routine analysis in quality control laboratory. Also, it is suitable for the determination of oxamniquine in spiked human plasma with minimum detection limit lower than the reported value. In addition, it could be applied to the determination of OXM in its pharmaceutical preparation.

\section{References}

1. Delgado JN, Remers WA (Eds) (1991) Wilson and Gisvold's text book of organic medicinal and pharmaceutical chemistry, 9th edn, $\mathrm{p} 184$

2. The USP Pharmacopoeia XXIII (1995) NF 18, The US Pharmaceutical Convention, Rockville, p.1120.

3. Hassan SM, Belal F, Sharf-El-Din M, Sultan M (1988) Spectrophotometric determination of some pharmaceutically nitro compounds in their dosage forms. Analyst 113:1807-1809

4. Bebawy LI, El-Kelani K, Abdel Fattah L, Ahmad AK (1997) Study of $7,7^{\prime}, 8,8^{\prime}$-tetracyanoquinodimethane charge transfer complexes with some lone-pair-donating drugs. J Pharm Sci 86:1030-1033

5. Rizk M, Belal F, Ibrahim F, Ahmed SM, El-Enany NM (2000) A simple kinetic spectrophotometric method for the determination of oxamniquine in formulations and spiked biological fluids. J Pharm Biomed Anal 23:503-513

6. Korolkovas A, Haraguchi T (1980) Rev. Farm. Bioquim Univ. Sao Paulo, 16, 12. Thro. Chem. Abstr. vol 94, pp 7846e, 1981

7. Woolhouse NM, Wood PR (1977) Determination of oxamniquine in serum. J Pharm Sci 66:429-430

8. Jun HW, Radwan MA (1985) Anal Lett 18:1345-1355

9. Pierri EG, Almeida AE, Gremiao MP (2001) Determination of oxamniquine in capsules by HPLC. J Pharm Biomed Anal 26:675-679

10. Masimirembwa CM, Hasler JA, Johansson I (1995), Inhibitory effects of antiparasitic drugs on cytochrome P450 2D6. Eur J Clin Pharmacol 48:35-38

11. Abushoffa MA, Clark BJ (1995) Resolution of the enantiomers of oxamniquine by capillary electrophoresis and high-performance liquid chromatography with cyclodextrins and heparin as chiral selectors. J Chromatogr 700:51-58

12. Noctor TA, Fell AF, Kaye B (1990), High-performance liquid chromatographic resolution of oxamniquine enantiomers: application to in vitro metabolism studies. Chirality 2:269-274

13. Fell AF, Noctor TA, Mama JE, Clark BJ (1988) Computer-aided optimisation of drug enantiomer separation in chiral highperformance liquid chromatography. J Chromatogr 434:377-384

14. Belal F, Aly FA (1995) Polarographic behavior and determination of oxamniquine in dosage forms. Electroanalysis 7:483-487

15. Mohamed MY, El-Gendy AE, El-Bardicy MG, Tawakol MS, Ahmed AKS (1996) Spectrosc Lett 29:299-319

16. Radi A, Belal F (1998) Reaction of electrogenerated oxamniquine radical anion with glutathione. J Electroanal Chem 441:39-42

17. Rizk M, Belal F, Ibrahim F, Ahmed SM, El-Enany NM (1999) Fluorimetric determination of oxamniquine in biological fluids. Il Farmaco 54:47-50

18. Ayad MM (1984) Spectrofluorimetric microdetermination of imidazoline derivatives using 1-dimethylaminonaphthaline-5sulphonylchloride. Analyst 109:431-1434

19. Putter J (1979) A fluorometric method for the determination of praziquantel in blood-plasma and urine. Eur J Drug Metab Pharmacokinet 4:143-148

20. Frei-Hausler M, Frei RW (1973) An investigation of fluorigenic labelling of chlorophenols with dansyl chloride. J Chromatogr $84: 214-220$

21. Lucca A, Gentilini G, Lopez-Silva S, Soldarini A (2000) Simultaneous determination of human plasma levels of four selective serotonin reuptake inhibitors By HPLC. Ther Drug Monit 22:271-276

22. Dennis Gmur J, Charles Bredl R, Sharon J, Steele SC, Donald R, Devanter V, Pasqua AN (2003) Determination of polymyxin $E_{1}$ in rat plasma by high-performance liquid chromatography. J Chromatogr B 789:365-372

23. Houdier S, Perrier S, Defrancq E, Legrand M (2000) A new fluorescent probe for sensitive detection of carbonyl compounds: sensitivity improvement and application to environmental water samples. Anal Chim Acta 412:221-233

24. Bagdonaite K, Viklund G, Skog K, Kovic M (2006) Analysis of 3 Amino-propionamide: apotential precursor of acrylamide. J Biochem Biophys Methods 69:215-221

25. Seiler N (1970) Methods Biochem Anal 18:259

26. Guidance for industry bioanalytical method validation. US Department of Health and Human Services, Food and Drug Administration, Center for Drug Evaluation and Research, Rockville, MD, May. 2001. http://www.fda.gov/eder/guidance/ 4252fnl.pdf (accessed September 1, 2004)

27. Miller JN, Miller JC (2005) Statistics and chemometrics for analytical chemistry, 5th edn. Prentice Hall, England, p 256

28. Iqbal A, Tauqir A (1991) Analytical profile of drug substances. In: Florey K (ed) vol 20. Academic, New York, p 623

29. Rose J (1964) Advanced physico-chemical experiments. Pitman, London 